\title{
SNAPSHOT
}

\section{Americans' views}

When asked whether they believe the Earth has been warming over the past 100 years, large percentages of Americans said yes, according to preliminary findings presented in November 2013 by researchers of the Stanford Woods Institute for the Environment at Stanford University (http://go.nature.com/bJn3PZ). It is a remarkable conclusion, challenging previous analyses that have often pointed to divisions in the climate change opinions held by the American public, with significant portions of sceptical views. But is the new data really contradicting evidence? A closer look at the details shows that there are significant differences between the Stanford study and previous analyses and therefore a direct comparison between them is probably not justified.

The new research is what social scientists call a 'secondary analysis', where existing data from various surveys are used in an aggregate analysis. In this particular case, the authors - Bo Maclnnis and Jon Krosnick of Stanford University collated data from 21 national, and multi-state surveys covering almost all of the USA, something unprecedented in the context of climate change research. These surveys were conducted between 2006 and 2013, mainly by Stanford University, to measure public opinion on different issues related to climate change. In the new study, the researchers were able to concatenate the data as the individual surveys asked the same question over time. And it is actually the wording that matters here. It is one thing to ask for personal beliefs about whether the Earth has warmed over the last 100 years, and another to ask respondents to describe whether they have heard or read about solid evidence documenting warming over the past few decades, as done by the Pew Research Center, for example a non-partisan fact tank that conducts public opinion polling and other empirical social science research around the world (http://go.nature.com/56bMLI). These two questions do not necessarily go together. Jon Krosnick (pictured) explains that in several cases the same participants asserted belief in warming over the past 100 years and no access to solid evidence about warming over the past decades.

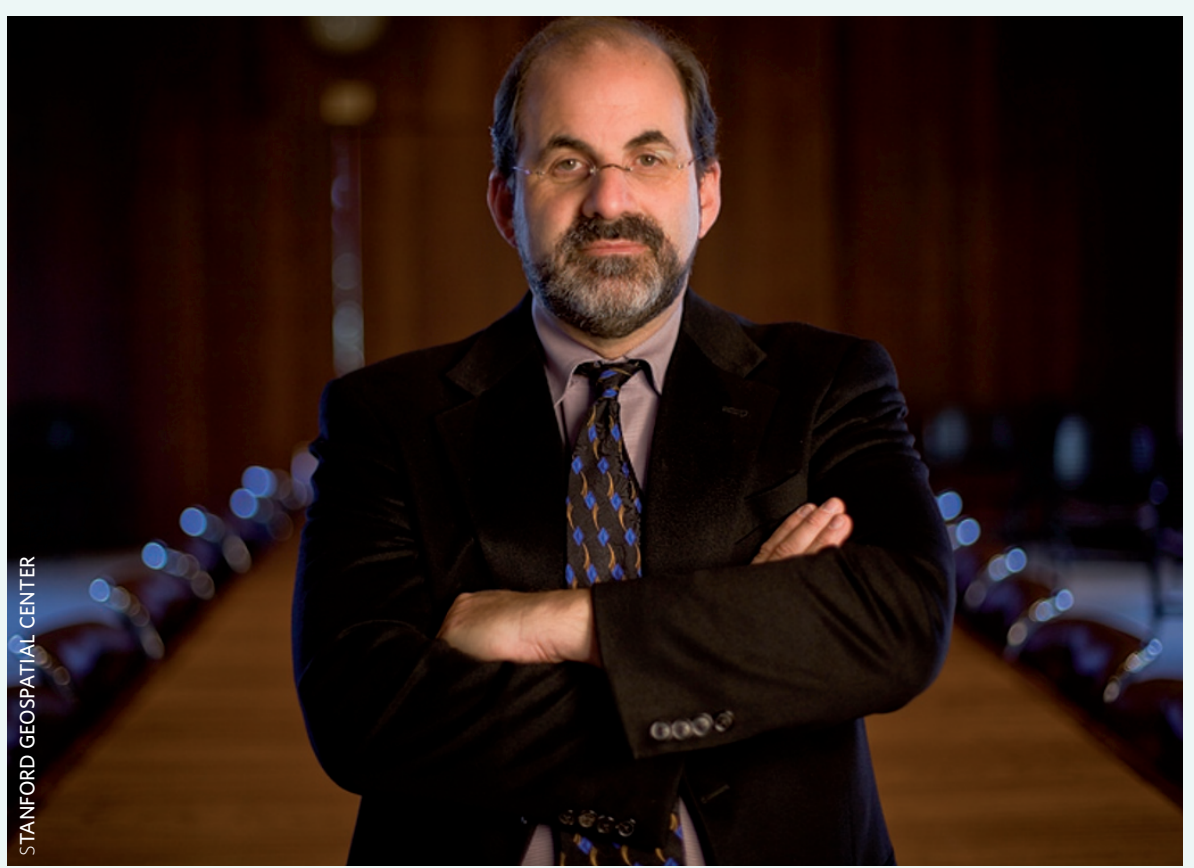

This is not only a sign that the US public is less divided on climate change than many think, it also shows that divergence between findings from different studies is often the consequence of the specific survey designs. We shouldn't expect different questions around climate change, as applied by different organizations, to deliver similar patterns of results as they might tap into quite different personal beliefs.

"We did not find even one state in which a majority of residents were consistently sceptical about climate change" Krosnick said. However, the results point to plenty of variation across states as the majorities varied from just above $50 \%$ to above $90 \%$. Apparently the researchers found some evidence that people in warmer states were more likely to believe that the Earth's temperature has been rising over the past century. People who live in states whose income is largely derived from the fossil fuel industry were more likely to oppose government restrictions on emissions by businesses. But Krosnick noted that these effects are relatively weak and explain only a small amount of the variation in opinions across states.

In addition to polarization, communication specialists sometimes focus on understanding whether public opinion about global warming fluctuates significantly over time, as this reveals whether, at specific moments in time, messaging campaigns have had impact. "Despite events such as hurricanes Katrina and Sandy in the US, AI Gore's movie, typhoon Hayan in the Philippines and Climategate in the UK, the proportions of Americans expressing particular opinions on climate change have been remarkably consistent over time", explained Krosnick. Of course there have been small ups and downs in the fractions of the public concerned about climate change, and these dynamics are observed among groups that show low trust in climate scientists. However, the new findings reveal significant levels of public support for a number of possible policy approaches to tackle climate change in the US - including a cap-and-trade system to limit emissions and tax breaks to facilitate renewable energy generation. It is clearly time for the US Congress to recognize what the American public, to a large extent, expect politicians to do about climate change.

MONICA CONTESTABILE 